
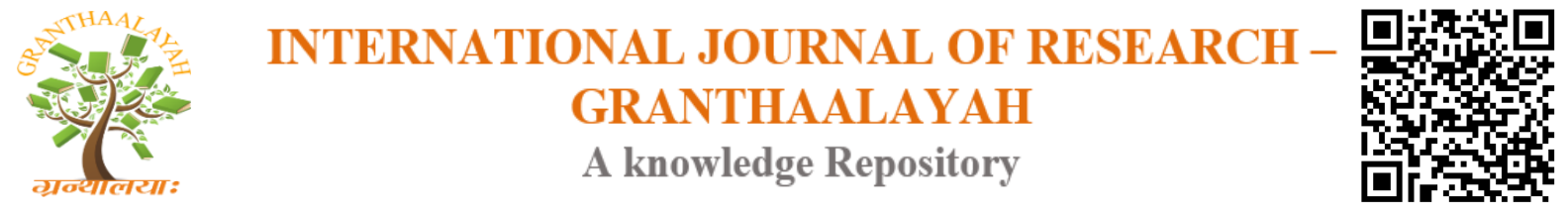

Social

\title{
EFFECTS OF ISOLATED AND COMBINED EFFECTS OF AEROBIC DANCING AND RESISTANCE TRAINING ON SYSTOLIC BLOOD PRESSURE OF TYPE-2 DIABETIC PATIENTS
}

\author{
Dr.D.Maniazhagu*1 \\ ${ }^{* 1}$ UGC-Research Awardee, Assistant Professor, Department of Physical Education and Health \\ Sciences, Alagappa University, Karaikudi, India
}

\begin{abstract}
The purpose of study was to find out the effects of isolated and combined effects of aerobic dancing and resistance training on systolic blood pressure of type- 2 diabetic patients. To achieve the purpose of the study, 60 type 2 diabetic patients from Karaikudi town, Sivaganga District, Tamilnadu were selected as subject at random. The study was formulated as pre and posttest random group design, in which sixty subject were divided into four equal groups. The experimental group-1 $(n=15$, AD, experimental group-2 $(n=15, R T)$, experimental group -3 $(\mathrm{n}=15, \mathrm{COM}-\mathrm{T})$ and group-4 $(\mathrm{n}=15, \mathrm{CG})$ served as a control group. In this study, three training programme were adopted as independent variable, i.e., aerobic dancing, resistance training and combined training. The systolic blood pressure was chosen as dependent variable. The collected pre and post data was critically analyzed with apt statistical tool of analysis of co-variance. The Scheffe's post hoc test was used to find out pair-wise comparisons between groups. The results of the present study proved that the three training interventions have produced significantly altered on systolic blood pressure.
\end{abstract}

Keywords: Aerobic Dancing; Resistance Training; ANCOVA; Systolic Blood Pressure; Scheffe's Post Hoc Test.

Cite This Article: Dr.D.Maniazhagu. (2017). "EFFECTS OF ISOLATED AND COMBINED EFFECTS OF AEROBIC DANCING AND RESISTANCE TRAINING ON SYSTOLIC BLOOD PRESSURE Of TYPE-2 DIABETIC PATIENTS.” International Journal of Research Granthaalayah, 5(10), 11-16. https://doi.org/10.29121/granthaalayah.v5.110.2017.2261.

\section{Introduction}

There is a global diabetes epidemic. Over 180 million people worldwide have diabetes, and the World Health Organization (2008b) predicts that by 2030 this number is likely to more than double. At least $65 \%$ of people with diabetes mellitus die from some form of heart or blood vessel disease (American Heart Association 2008a). Also, diabetes is among the leading causes of kidney failure; $10 \%$ to $20 \%$ of people with diabetes die of kidney failure(World Health Organization 2008b).Over 48 million adults in Europe and 17 million adults in the United States 
have diabetes, and the prevalence is increasing (American Heart Association 2008a; British Heart Foundation Health Promotion Research Group 2005).Diabetes, the most common endocrine disorder, affects multiple organs and body functions, causing serious health complications, such as renal failure, heart disease, nerve damage, stroke, and blindness. The body cannot control the level of circulating blood glucose because of either insufficient insulin production or inadequate response by organs to circulating levels of insulin, the major hormone controlling the body's glucose homeostasis. Some of the most characteristic symptoms associated with the onset of diabetes include frequent urination, excessive thirst, and fatigue. Diabetes is diagnosed when the level of glucose in the blood is greater than $7.0 \mathrm{mmol} / \mathrm{L}$ (fasting). Three major types of diabetes have been defined: type 1 or insulin -dependent diabetes mellitus, type 2 or non-insulin-dependent diabetes mellitus, and gestational diabetes. In this study an attempt is made to find out the effects of isolated and combined effects of aerobic dancing and resistance training on flexibility of type-2 diabetic patients.

\section{Materials and Methods}

The study was formulated as pre and post test random group design, in which sixty subject were divided into four equal groups. The experimental group-1 ( $n=15$, AD) underwent aerobic dancing the experimental group-2 $(n=15, \mathrm{RT})$ underwent resistance training, experimental group - $3(n=15, A D+R T)$ underwent combined training of aerobic dancing and resistance training (COM-T) and group-4 ( $\mathrm{n}=15, \mathrm{CG})$ served as a control group did not undergo any training. In this study, three training programme were adopted as independent variable, i.e., aerobic dancing, resistance training and combined training. The systolic blood pressure was chosen as dependent variable. It was tested by sphygmomanometer and recorded in $\mathrm{mmHg}$. The selected three treatment groups were performed twelve weeks, as per the stipulated training program. The condition of systolic blood pressure was tested before and after the training period. The collected pre and post data was critically analyzed with apt statistical tool of analysis of co-variance, for observed the significant adjusted post-test mean difference of three groups. The Scheffe's post hoc test was used to find out pair-wise comparisons between groups. The patients were involved with their respective training for a period of twelve weeks.

\section{Results}

Table 1: The Results of Analysis of Covariance on Systolic Blood Pressure of Different Groups (Score in $\mathrm{mmHg}$ )

\begin{tabular}{|c|c|c|c|c|c|c|c|c|c|c|}
\hline \multicolumn{2}{|c|}{ Test Conditions } & $\begin{array}{c}\text { Group } 1 \\
\text { AD }\end{array}$ & $\begin{array}{c}\text { Group } 2 \\
\text { RT }\end{array}$ & $\begin{array}{c}\text { Group } 3 \\
(\mathrm{AT}+\mathrm{RT})\end{array}$ & $\begin{array}{c}\text { Group } 4 \\
\text { CG }\end{array}$ & SV & SS & Df & MS & $\begin{array}{c}\text { 'F' } \\
\text { Ratio }\end{array}$ \\
\hline \multirow{2}{*}{ Pre test } & Mean & 141.53 & 141.47 & 140.67 & 141.47 & B & 7.53 & 3 & 2.51 & \multirow{2}{*}{0.31} \\
\hline & S.D. & 3.27 & 3.81 & 1.76 & 1.89 & $\mathrm{~W}$ & 446.80 & 56 & 7.98 & \\
\hline \multirow{2}{*}{ Post test } & Mean & 133.93 & 137.80 & 130.73 & 142.80 & B & 1216.32 & 3 & 405.44 & \multirow{2}{*}{$55.56^{*}$} \\
\hline & S.D. & 2.96 & 3.67 & 1.83 & 1.90 & $\mathrm{~W}$ & 408.67 & 56 & 7.30 & \\
\hline \multirow{2}{*}{$\begin{array}{l}\text { Adjusted } \\
\text { post test }\end{array}$} & \multirow{2}{*}{ Mean } & & & & & B & 1189.62 & 3 & 396.54 & \multirow{2}{*}{$193.39 *$} \\
\hline & & 133.63 & 137.56 & 131.14 & 142.94 & W & 112.77 & 55 & 2.05 & \\
\hline
\end{tabular}


* Significant at .05 level of confidence. The required table value for test the significance was 2.77 and 2.77 with the df of 3 and 56, 3 and 55.

\subsection{Results on Systolic Blood Pressure}

The pre test mean and standard deviation on systolic blood pressure scores G1, G2, G3 and G4 were $141.53 \pm 3.27,141.47 \pm 3.81,140.67 \pm 1.76$ and $141.47 \pm 1.89$ respectively. The obtained pre test $F$ value of 0.31 was lesser than the required table $F$ value 2.77 . Hence the pre test means value of aerobic dancing; resistance training, combined training and control group on systolic blood pressure on before start of the respective treatments were found to be insignificant at 0.05 level of confidence for the degrees of freedom 3 and 56. Thus this analysis confirmed that the random assignment of subjects into four groups were successful.

The post test mean and standard deviation on systolic blood pressure of G1, G2, G3 and G4 were $133.93 \pm 2.96,137.80 \pm 3.67,130.73 \pm 1.83$ and $142.80 \pm 1.90$ respectively. The obtained post test $F$ value of 55.56 was higher than the required table $F$ value of 2.77 . Hence the post test means value of aerobic dancing; resistance training, combined training and control group on systolic blood pressure on after the treatments were found to be significant at 0.05 level of confidence for the degrees of freedom 3 and 56. The results proved that the selected three training interventions namely aerobic dancing; resistance training and combined training were produced significantly altered among the treatment group.

The adjusted post test means on systolic blood pressure scores of G1, G2, G3 and G4 were 133.63, 137.56, 131.14 and 142.94 respectively. The obtained adjusted post test $F$ value of 193.39 was higher than the required table $F$ value of 2.77. Hence adjusted post test means value of aerobic dancing; resistance training, combined training and control group on systolic blood pressure were found to be significant at 0.05 level of confidence for the degrees of freedom 3 and 55.The results confirm that the selected three training interventions namely aerobic dancing; resistance training, and combined training on systolic blood pressure were significantly altered.

Table 2: The Results of Scheffe's Post Hoc Test Mean Differences on Systolic Blood Pressure among Three Groups (Scores in $\mathrm{mmHg}$ )

\begin{tabular}{|l|l|l|l|l|l|}
\hline $\begin{array}{l}\text { Group 1 } \\
\text { AD }\end{array}$ & $\begin{array}{l}\text { Group 2 } \\
\text { RT }\end{array}$ & $\begin{array}{l}\text { Group 3 } \\
\text { AD+RT }\end{array}$ & $\begin{array}{l}\text { Group 4 } \\
\text { C G }\end{array}$ & $\begin{array}{l}\text { Mean } \\
\text { Differences }\end{array}$ & $\begin{array}{l}\text { Confidence } \\
\text { Interval Value }\end{array}$ \\
\hline 133.63 & 137.56 & - & - & $3.92^{*}$ & 1.85 \\
\hline 133.63 & - & 131.14 & - & $2.49^{*}$ & 1.85 \\
\hline 133.63 & - & - & 142.94 & $9.30^{*}$ & 1.85 \\
\hline- & 137.56 & 131.14 & - & $6.42^{*}$ & 1.85 \\
\hline- & 137.56 & - & 142.94 & $5.38^{*}$ & 1.85 \\
\hline- & - & 131.14 & 142.94 & $11.80^{*}$ & 1.85 \\
\hline
\end{tabular}

* Significant at .05 level of confidence.

The table 2 shows the paired mean differences of aerobic dancing; resistance training, combined training and control group on systolic blood pressure. The paired wise comparisons results as follows. 


\subsection{Result of Scheffe's Post Hoc Test on Systolic Blood Pressure}

First comparison: Group 1 and Group 2: The pair wise mean difference of group 1 and group 2 values 3.92 was higher than the confidential interval value of 1.85 . Hence the first comparison was significant. The results of this comparison clearly proved that both training have produced significantly different effect on systolic blood pressure.

Second comparison: Group 1 and Group 3: The pair wise mean difference of group 1 and group 3 values 2.49 was higher than the confidential interval value of 1.85 . Hence the second comparison was significant. The results of this comparison clearly proved that both training have produced significantly different effect on systolic blood pressure.

Third comparison: Group 1 and Group 4: The pair wise mean difference of group 1 and group 4 values 9.30 was higher than the confidential interval value of 1.85 . Hence the third comparison was significant. The results of this comparison clearly proved that aerobic training have produced significantly different effect on systolic blood pressure than the control group.

Fourth comparison: Group 2 and Group 3: The pair wise mean difference of group 2 and group 3 values 6.42 was higher than the confidential interval value of 1.85 . Hence the fourth comparison was significant. The results of this comparison clearly proved that both training have produced significantly different effect on systolic blood pressure.

Fifth comparison: Group 2 and Group 4: The pair wise mean difference of group 2 and group 4 values 5.38 was higher than the confidential interval value of 1.85 . Hence the fifth comparison was significant. The results of this comparison clearly proved that resistance training have produced significantly different effect on systolic blood pressure than the control group.

Sixth comparison: Group 3 and Group 4: The pair wise mean difference of group 3 and group 4 values 11.80 was higher than the confidential interval value of 1.85 . Hence the sixth comparison was significant. The results of this comparison clearly proved that combined training have produced significant different effect on systolic blood pressure than the control group.

\section{Discussion on Findings}

The therapeutic benefits of regular exercise in the treatment of type 2 diabetes have long been recognized. As early as 1919, there were reports of exercise lowering blood glucose concentrations in diabetic patients and improving glucose tolerance. In the 1935 edition of The Treatment of Diabetes Mellitus by Joslin and colleagues, exercise was recommended in the everyday treatment of diabetes." From the epidemiological studies discussed in the previous sections, clear that regular moderate-intensity exercise can be an important part of a regimen to prevent and treat type 2 diabetes. Regular physical activity potentiates the effects of diet and oral anti hyperglycemic therapy examine (e.g., metformin and sulfonylurea) to lower glucose levels and improve insulin sensitivity in obese people type 2 diabetes. Many health benefits that regular physical activity provides in the prevention of chronic metabolic diseases, such as type 2 diabetes may be attributable to the overlapping actions of individual exercise sessions and longterm adaptations to exercise training. As mentioned elsewhere, acute exercise produces major 
effects on whole-body glucose disposal and skeletal muscle glucose uptake and metabolism. However, the elevated insulin-stimulated glucose disposal rates, responsible for the improved insulin sensitivity, tend to disappear after about 5 to 7 days of inactivity. Hence, the effects of exercise training in increasing insulin action are transient and require a regular and constant practice of physical activity. In addition to improving glucose tolerance and insulin resistance, exercise training has other beneficial effects, such as improving cardiovascular fitness, lowering blood pressure, improving blood lipid profiles, promoting weight loss, reducing abdominal and intra-abdominal fat (a major risk factor for insulin resistance), and promoting a sense of wellbeing, all of which are known to be associated with diabetes. Therefore, regular physical activity improves morbidity and mortality in people with type 2 diabetes. Multiple factors may modulate the response to exercise training in subjects with diabetes, such as the degree of insulin resistance and insulin deficiency, the frequency and intensity of exercise, the adherence to diet, and weight loss. Insulin sensitivity and the rate of glucose disposal are related to cardio respiratory fitness even in older persons. The additional potential beneficial effects of exercise training to lower cardiovascular risk in people with type 2 diabetes may reduce the risk of macro vascular or atherosclerotic complications typical of diabetes.

The present research has been useful to confirm many of the finding of earliest studies on this subject. The major findings of earlier studies are given here for comparison with the present findings.

Tarek Ammar (2015) conducted a study on effects of aerobic exercise on blood pressure and lipids in overweight hypertensive postmenopausal women. He found that, morning aerobic exercises were more effective in reducing the blood pressure and lipids than afternoon exercises in overweight hypertensive postmenopausal women.

Yasuaki Hayashino, Jeffrey L. Jackson, Norio Fukumori, Fumiaki Nakamura Shunichi Fukuhara (2012) conducted a study on effects of supervised exercise on lipid profiles and blood pressure control in people with type 2 diabetes mellitus: A meta-analysis of randomized controlled trials. They concluded that supervised exercise is effective in improving blood pressure control, lowering LDL-C, and elevating HDL-C levels in people with diabetes

Akbar Ghalav, Saeid Shakeriyan, Akram Monazamnezhad and Mojtaba Delaramnasab (2014) studied the effect of resistance training on cardio-metabolic factors in males with type 2 diabetes. Findings of this study confirmed the positive influence of resistance training to control blood glucose and blood pressure in males with type 2 diabetes.

\section{Conclusions}

The results of this study indicate that the selected three training interventions namely aerobic training, resistance training and combined training would produce significantly altered on systolic blood pressure to the type 2 diabetic patients. However the combined training had influenced greater development of systolic blood pressure.

Further aerobic training has produced the significant alteration in the condition of systolic blood pressure than the resistance training. 
The least alteration was observed in the resistance training on systolic blood pressure than the control group. No development was observed in systolic blood pressure on control group.

\section{References}

[1] Akbar Ghalavand, SaeidShakeriyan, AkramMonazamnezhad and MojtabaDelaramnasab , "The Effect of Resistance Training on Cardio-Metabolic Factors in Males with Type 2 Diabetes", Jundishapur Journal of Chronic Disease Care. ,2014 , 3(4), e23346 , DOI:10.17795/jjcdc-23346

[2] American Heart Association.2008a. Diabettetes mellitus-Statistics. Statistical fact sheet-risk factors 2008 update.

[3] British heart foundation Health Promotion Research Group.2005.Europien cardiovascular disease statistics, 2005 edition.

[4] TarekAmmar, (2015) "Effects of aerobic exercise on blood pressure and lipids in overweight hypertensive postmenopausal women", Journal of Exercise Rehabilitation; 11(3): 145-150.

[5] YasuakiHayashino, Jeffrey L. Jackson, Norio Fukumori , Fumiaki Nakamura, Shunichi Fukuhara (2012)"Effects of supervised exercise on lipid profiles and blood pressure control in people with type 2 diabetes mellitus: A meta-analysis of randomized controlled trials", Diabetes Research and Clinical Practise, Vol.98, Issue 3, pp. 349-360

[6] World Health Organisation.2008b.Diabetes.Fact sheet no.312.

\footnotetext{
*Corresponding author.

E-mail address: drmaniazhagu@ gmail.com
} 